\title{
The Substitution Effect of Mobile Games on Console Games: An Empirical Analysis of the Japanese Video Game Industry
}

\author{
Shinichi Yamaguchi ${ }^{1} \cdot$ Kotaro Iyanaga $^{2} \cdot$ Hirohide Sakaguchi $^{2} \cdot$ \\ Tatsuo Tanaka ${ }^{2}$
}

Received: 18 January 2017/ Accepted: 29 October 2017/Published online: 9 November 2017

(C) The Author(s) 2017. This article is an open access publication

\begin{abstract}
In this paper, we discuss the substitution effects between mobile games and console games. We estimate such effects by a fixed-effect regression with instrumental variables using panel data of about 100,000 observations. The results showed that the substitution effects of playing smart devices on 3DS, Wii, and PSP were recognizable, but did not have significant effects on PS3, and the substitution effects on PSP were very small. Therefore, mobile games had a substitution effect on casual console games, or on console games in which the play situation resembled mobile games. In addition, the substitution effects were at most about 0.1 . The substitution effects were small. Our results indicate that mobile games represent the pioneers in the new market of gaming at least during our observation period. But new games and traditional games will coexist for a while.
\end{abstract}

Keywords Mobile games · Console games · Gaming industry · Substitution effect $\cdot$ Empirical analysis $\cdot$ Panel data $\cdot$ Instrumental variables method

Shinichi Yamaguchi

syamaguchi@glocom.ac.jp

Kotaro Iyanaga

koutaroubasukura@keio.jp

Hirohide Sakaguchi

hhhsakaguchi@gmail.com

Tatsuo Tanaka

tatsuo@econ.keio.ac.jp

1 Center for Global Communications, International University of Japan, 6-5-21 Minato-ku, Roppongi, Tokyo 106-0032, Japan

2 Faculty of Economics, Keio University, 2-15-45 Mita, Minato-ku, Tokyo, 108-8345, Japan 


\section{Introduction}

New services are created because of the rapid growth of certain new technologies. Therefore, traditional producers are always fearful that such new services will be a threat to their business and drive their customers away from their markets. This phenomenon has occurred in various industries many times.

In the music market, for example, the media used in music distribution changed from records to cassettes to CDs (compact disks), and then to digital distribution. Records were created in the early 1900's, and changed the way people enjoyed music. In 1983, for example, records were $44.6 \%$ of the audio formats in America according to the Recording Industry Association of America (RIAA). However, when people listened to music with records, they needed a record player and it was difficult to enjoy records outside of the house. As an alternative device to records, cassettes were invented which enabled people to listen to music in an area distant from a record player, for example, in their automobiles.

After records and record players, from around 1980, CDs became the next big thing, and they soon became the main innovation in the music industry. CDs had a better sound quality, and they were easier to carry. Actually, CDs had a $95.5 \%$ share of the America music industry in 2003. After around 2005, however, people started to use streaming or downloading services because smart devices and digital distribution spread (e.g., iTunes). As a result, in 2013, the share of CDs had decreased to $30.4 \%$, and that of downloading, on-demand streaming, and paid subscriptions had reached $51.7 \%$.

When a new business is created due to innovative technology like this, economists get interested in how large an influence the new business model will have on the existing one. Nguyen et al. [1] showed that music streaming services do not have a significant effect on sales of CDs, but have a positive effect for sales of concert tickets. Koh et al. [2] showed that legitimate digital music decreased the negative influence on music CDs caused by music that is pirated and subject digital music substituted for music CDs. Koh et al. [3] estimated the substitution relationship between purchasing music online and buying CDs in a local retail store. They used data from the books sold on Amazon, which were the top sellers in 1497 local bookstores in America. Goldfarb et al. [4] analyzed the substitution between the online and offline advertising markets. The authors showed that online advertising substitutes the offline advertising, but the opposite was not true. As shown in these sources, new business strategies with new products win over old ones in various industries.

How about the case of the game industry? Recently, we have seen a large innovation in the game industry, particularly, in the emergence of mobile games on smartphones. The business strategy of mobile games on smartphones is different from the business strategy used for traditional console games. Will we see the substitution of major players or business strategies change just as they did in the media of music? The goal of this paper is to evaluate the impact of new mobile games by estimating the substitution effect using large-scale panel survey data. Our 
conclusion is that substitution effect of mobile games for console games is limited, so that new games and traditional games will coexist for a while.

This paper is divided into five sections. Section 2 explains the data we used. Section 3 shows the model of our analyses. Section 4 shows the result of analyses. Finally, in Sect. 5, we conclude with a discussion about the future of the gaming industry.

\section{The Video Game Industry and the Change in the Business Model}

There are three types of games in the video game industry ${ }^{1}$. First, PC games (including online games) played on a personal computer. Second, console games played on game-specific devices such as a Family Computer (Nintendo), Nintendo DS (Nintendo), Wii (Nintendo), PlayStation ( $\mathrm{SIE}^{2}$ ), PlayStation Vita (SIE), or an Xbox (Microsoft). Until recently, these types of video game consoles and software have been major products in the game industry. Third, mobile games have played on general purpose communication devices such as feature phones, smartphones, and tablet computers. In Japan, mobile games were created around 2000 when NTT provided feature phones with an IP connection service called the "i-mode." Mobile games deploy many elements of social interaction in the gaming system such as ranking among users and mechanisms for items that create friendship.

One of the features of many mobile games is the "freemium" or "non-package business model," especially gacha, or payment items. Freemium is a word that compounds "free" and "premium," which was introduced by Wilson in $2006^{3}$. Its business model is that the baseline service is free to use and users pay charges only to use premium services [5]. The system of charges is a monthly fee, or occasionally payment items with a higher service. Freemium began in the PC online game market. In the mobile phone market, gacha started in the feature phone era.

Freemium has been adopted by many online services such as music platforms, movie platforms, online review sites, and message applications. For instance, in Japan, Cookpad is a communication site using freemium to share recipes and techniques for cooking. The users can write and search recipes for free. However, members who use this service for free cannot use a premium services such as researching popular recipes and calculating calories, or the amount of salt, for example, used in a recipe. This high-end (premium) service costs 280 yen per month and an even higher service "Pro's recipes" costs 360 yen per month, which provides recipes by cooking experts. The number of paid users has reached 1.7 million at the time of writing this paper.

The main characteristic of mobile games' freemium model is billing for digital goods. Users of mobile games can play its contents for free, but the mobile game publishers gradually make their games more difficult to play without paying a

\footnotetext{
1 We exclude the arcade game in this paper, because it is not a video game that individuals possess and play.

2 Sony Interactive Entertainment. It was called Sony Computer Entertainment until March 2016.

3 Wilson, F., My Favorite Business Model. AVC. http://avc.com/2006/03/my_favorite_bus/.
} 
charge. For example, getting rare characters and items becomes more difficult as players proceed with a game story. Therefore, players who want to play efficiently or proceed to a high ranking of users end up paying charges to get premium characters and items. The major way to buy premium characters is to purchase them at the store or to draw them in a lottery called gacha. Davidovici-Nora [6] showed that the business model for mobile games is based on the network effect among users and price discrimination of those premium service and items.

There are several articles that discuss the relationship between console games and mobile games. Rayna et al. [7] discuss five differences between console games and mobile games: value proposition, value creation, value delivery, value capture, and value communication. Based on these differences, the mobile games have created a new business model in the game industry, and the authors of [7] show that a new strategy is necessary to manage the competition. Mobile games are considered the driving force for innovation, especially as a new business model. Freemium is actually a new business model which has never been seen before in console games and is welfare improving from the view of economic efficiency [8]. Rayna et al. [7] also compared mobile games with console games as a business model from the viewpoint of microeconomics and macroeconomics. Joost van Dreunen [9] showed the change of business models in the game industry from 1980 to 2011. Ernkvist [10] emphasized that the business model of mobile games is a destructive innovation these days, that is, it lowers the entry barrier to the market dramatically.

From another point over view, it has been pointed out that mobile games have a higher profit rate than console games. Table 1 shows the ordinary income rate of console games and mobile game publishers in Japan. As seen in Table 1, the ordinary income rate of Nintendo is $5.7 \%$ and that of SIE is 3.0\%. In contrast, the mobile game companies have a larger profit rate than Nintendo and SIE. Gungho, Colopl, and Mixi in particular show a much higher rate than the console game companies: Gungho: $47.0 \%$, Mixi: $45.4 \%$, and Colopl: $44.7 \%$. The rate of DeNA, Cyber Agent, and GREE is around 15\%, but they provide other services in addition to games. Therefore, we can safely say that the ordinary income rate of these mobile game publishers is higher than that of most console game publishers.

Here we can ask: Is there a substitution effect for mobile games? Figure 1 shows the market size of the game industry in Japan. The market size of console games reached its maximum in 2007 and has gradually decreased since then. In contrast, the market size of mobile games has increased its size. The games for smartphones have expanded drastically from 2012. As a result, the market size of mobile games has a $70 \%$ share in the Japanese game industry.

This figure indicates that mobile games will eventually substitute for console games completely. However, the negative growth rate of the market size of console games is much smaller than the positive growth rate of the market size of mobile games. In addition, interview surveys with game companies and experts in the gaming business show a differentiation between mobile games and console games, so that the two types of games can coexist together and the substitution effects of mobile games on console games are limited. 
Table 1 The ordinary income rate of video game publishers and mobile game publishers

\begin{tabular}{llc}
\hline & Company & Ordinary income rate (\%) \\
\hline Console game publishers & Nintendo & 5.7 \\
& SIE & 3.0 \\
& SQUARE ENIX & 11.8 \\
Mobile game publishers & DeNA & 14.5 \\
& Cyber agent & 11.4 \\
& Colopl & 44.7 \\
& Gungho & 47.0 \\
& GREE & 15.1 \\
& Mixi & 45.4 \\
\hline
\end{tabular}

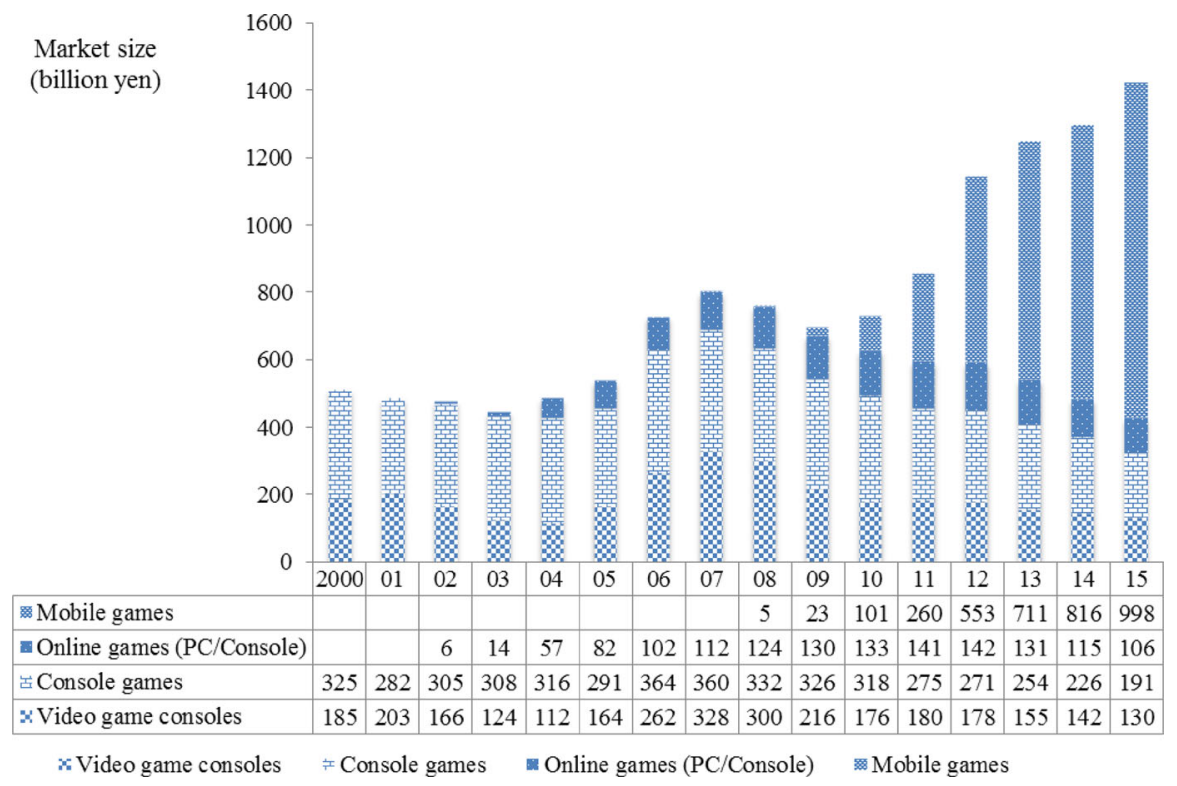

Fig. 1 The market size of the video game industry in Japan Source: Famitsu game white paper and JOGA Online Game Market Research Report (color figure online)

If this view is right, Fig. 1 can be interpreted so that mobile games are exploiting new markets. The mobile games attract casual game players who do not have much interest in the game and do not always buy console games in the game market, which is a factor for success of mobile games [7]. Moreover, Heier [11] and Vankka [12] show similar results by discussing how mobile games bring in casual users who were included in console games in the market and who may develop new markets. Based on this perspective, the common view is that a new business model will beat out the old model that may no longer work in the game industry. In this paper, we test this hypothesis through empirical analysis. 
Hypothesis: Mobile games will have few substitution effects on console games.

\section{Estimation Model}

In this section, we explain the estimation model of players' choices for console games vs. mobile games. Mobile games are defined as games played on smart devices ${ }^{4}$. Equation (1) shows whether individual $i$ plays console game $j$ when individual $i$ plays mobile games at time $t$ :

$$
Y_{i j t}=\alpha+S_{i t} \beta^{1}+C_{i t} \beta^{2}+P_{i t} \beta^{3}+Z_{t}+F_{i}+\varepsilon_{i t} .
$$

where $Y_{i j t}$ shows whether individual $i$ plays the console game $j$ at time $t, S_{i t}$ is the vector of dummy variables which indicates whether individual $i$ plays mobile games on her or his smart device at time $t$ ( $S_{i t}$ is 1 if an individual $i$ plays mobile games), $C_{i t}$ is the vector of dummy variables which indicate whether individual $i$ plays home video console games ${ }^{5}$ at time $\mathrm{t}^{6}\left(C_{i t}\right.$ is 1 if individual $i$ plays home video console games), and $P_{i t}$ is the vector of dummy variables which indicate whether individual $i$ plays handheld console games ${ }^{7}$ at time $\mathrm{t}^{8}\left(P_{i t}\right.$ is 1 if an individual $i$ plays handheld console games). $Z_{t}$ denotes exogenous shock at time $t$, and $F_{i}$ represents the personal fixed effect.

We focus on the parameter $\beta^{1}$ of vector $S_{i t}$ in this study. $\beta^{1}$ represents a substitution effect in which playing mobile games affects the playing of console games, and $-1 \leq \beta^{1}<0$. If $\beta^{1}=-1$, mobile games are the perfect substitution good of console games.

However, the endogeneity problem exists when we estimate this model (1). The endogeneity problem means that the error term is correlated with the independent variables. If the endogeneity problem occurs, the ordinary least squares method does not lead to the correct result, and if there is a positive correlation, the result is an overestimation [13]. For example, in Eq. (1), there is the possibility that individual $i$ plays both the mobile games and the console games at time $t$ because individual $i$ likes games or has much leisure time at time $t$. In this case, the error term is correlated with the independent variables.

For the above reasons, the estimation model includes fixed effects $F_{i}$, which can deal with the endogenous problem from unobservable personal preferences. Furthermore, we use $Z_{t}$ in the model and deal with the endogenous problem of time change. In addition, we adopt the method of an instrument variable (the IV method) for other endogenous problems which $F_{i}$ and $Z_{t}$ cannot control. The IV method is a method of ensuring the conformity of the estimation using IVs that are correlated with independent variables, but not correlated with error terms.

\footnotetext{
$\overline{4}$ In this study, smart devices are defined as smart phones and tablets.

5 Home video game consoles are video game devices used by home gamers (e.g. PlayStation3).

${ }^{6}$ When game $j$ is the home video console game, we remove $j$ from this vector.

7 Handheld game consoles are portable video game consoles (e.g. Nintendo 3DS).

8 When game $j$ is the handheld console game, we remove $j$ from this vector.
} 


\section{Data}

We used questionnaire survey data from gameage R\&I Co., Ltd., which is a think tank specialized in games. Around fifty thousand people all over Japan answered this questionnaire regarding their personal information such as gender, age, ownership of smart devices and video game consoles as well as their game play status. The survey was conducted for 13 months. Since part of the sample is replaced with new samples in each new survey, the data are unbalanced panel data.

This study uses the questionnaire of respondents for 13 months from August 2014 to August 2015, and we organized the panel data with individuals as a group. We obtained the information about whether they play home video game consoles, whether they own the home video game consoles, whether they play with handheld game consoles, whether they own the handheld console game, whether they play mobile games, and whether each has a smart device.

Table 2 shows the number of observations for each group. In Table 2, the number of observations of people in their 10 and $20 \mathrm{~s}$ is much smaller than in their 30,40 , and $50 \mathrm{~s}$. However, the total number of observations in young people is larger than for people in their 30 and $50 \mathrm{~s}$. The main players of mobile games are in their 30-40 s.

In this research, we analyze four home video game consoles, PlayStation3 (PS3), PlayStation4 (PS4), Wii, and WiiU. We removed XBOX360 and XBOXone because few people have these devices in Japan, so their sample size is too small to include. In addition to home consoles, we analyzed Nintendo 3DS (3DS), PSP, and PSVITA as handheld console games, and also the iPhone, the Android smartphone, and the iPad as smart devices.

The rate of playing games on each hardware and that of hardware ownership is provided in Table 3. Table 3 shows that the playing rate on the Android and iPhone is high, and this tendency is due to high ownership. Ownership of the iPhone and Android is especially high. Moreover, among the game machines, previous generation console ownerships of PS3, Wii, and PSP are also high.

Next, in order to confirm the influence of playing console games vs. playing mobile games on smart devices, the relation between playing mobile games and console games is shown in Fig. 2. Here, we use 3DS as the console game.

In Fig. 2, the upper bars represent the mobile games play rate in the sample of players who are playing 3DS at time $t$, and the lower bars are the players in the sample who do not play 3DS at time $t$. A comparison of the two bars shows that the sample of players playing 3DS has a higher rate of playing mobile games on smart devices.

However, considering the time constraints of the players, it is hard to interpret a truly positive correlation. It is more plausable that the endogeneity problem occurs in this figure. In this case, the endogeneity problem is: "Individual $i$ plays video games in both 3DS and smart devices because s/he likes video games", or "Individual $i$ has leisure time in period $t$, so s/he plays video games in both 3DS and with the smart devices." Therefore, we estimate the mobile games' substitusion effects with a fixed-effect model using the IV method in Sect. 5. 
Table 2 Playing rate and ownership rate

Table 3 Playing rate and ownership rate

\begin{tabular}{lll}
\hline Age (s) & Male & Female \\
\hline 10 & 47,379 & 49,179 \\
20 & 37,205 & 36,910 \\
30 & 81,451 & 73,871 \\
40 & 125,698 & 78,428 \\
50 & 94,922 & 49,455 \\
\hline
\end{tabular}

\begin{tabular}{lcc}
\hline Hardware & Playing rate $(\%)$ & Ownership rate $(\%)$ \\
\hline Android & 15.8 & 36.3 \\
iPhone & 14.0 & 27.9 \\
iPad & 3.5 & 11.1 \\
PS3 & 5.9 & 14.4 \\
PS4 & 1.8 & 2.8 \\
Wii & 4.5 & 23.8 \\
WiiU & 3.2 & 6.0 \\
3DS & 8.7 & 18.2 \\
PSP & 2.8 & 13.9 \\
PS Vita & 2.5 & 4.9 \\
Observations & 674498 & \\
\hline
\end{tabular}

\section{Android}
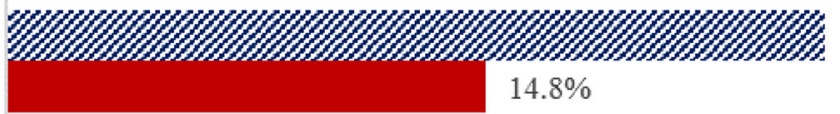

iPhone

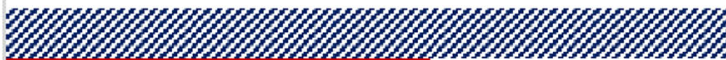

\section{$22.7 \%$}

iPad

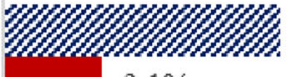

$8.6 \%$

$3.1 \%$

$0.0 \%$

$5.0 \%$

$10.0 \%$

$15.0 \%$

$20.0 \%$

$\boldsymbol{*}$ the sample of playing 3DS $\quad \boldsymbol{a}$ the sample of not playing 3DS

Fig. 2 Mobile games play rate on each smart device (color figure online) 
Table 4 Characteristics of the video game consoles

\begin{tabular}{lll}
\hline & SIE & Nintendo \\
\hline Home video game consoles & PS3 & Wii \\
Handheld game consoles & PSP & 3DS \\
\hline
\end{tabular}

\section{Estimation Results}

By also taking into consideration Sects. 2, 3, and 4, this section shows the estimation results of Eq. (1). We use PS3, Wii, 3DS, and PSP for the console game $Y_{i j t}$, which is the dependent variable. The reason for this is that these games are the top two consoles with a high play rate for home video game consoles and handheld game consoles. Furthermore, their developers are different. This situation is shown in Table 4.

Before conducting our estimation, we need to find instrumental variables (IV). The required condition of the IV is correlated with independent variables, but is not correlated with error terms. We use whether or not individual $i$ owns hardware $k(k$ is other than $j$ ) as the IV of each endogenous variable (the vectors $C_{i t}$ and $P_{i t}$ do not include the console game $j$ ) and whether or not individual $i$ plays the video game in hardware $k$ at time $t$. Whether individual $i$ owns hardware $k$ affects whether or not $\mathrm{s} /$ he plays the video game on that hardware $k$, but does not affect whether s/he plays the video game on console $j$, so owning hardware is correlated with the independent variables, but is not correlated with the error terms. For these reasons, whether or not individual $i$ owns hardware $k$ is appropriate as the IV.

Tables 5 and 6 show the fixed-effect method estimation result of Eq. (1). In Table 5, the coefficients are from the standard fixed-effect method, and from the IV fixed-effect method in Table 6 . In Table 5, the column $<1>$ shows the result when the dependent variable is PS3; column $<2>$ shows the result when what is? Wii; column $<3>$ shows the result when what is? 3DS, and column $<4>$ shows the result when what is? PSP. In Table 6 , columns $<5>\sim<8>$ correspond to $<1>\sim<4>$. When we estimate Eq. (1), every dependent variable is removed from the independent variables. In addition, the sample represents the owners of the console games as the dependent variables: in column $<1>$, the results refer to owners of PS3, and in column $<2>$, owners of Wii.

By comparing Tables 5 and 6 , we see that Table 5 does not use the instrument variables for the smart devices, and the video game consoles have significantly positive coefficients, so most of them are in complementary relationships. However, due to time restrictions, it is difficult to really see if there are complementary relationships. Since not controlling the endogeneity problem gives rise to overestimations, we adopt the results in Table 5.

As shown in Table 6, most of the parameters of the month dummies are significantly negative. These dummies are based on December because consumers tend to play the console games more during the Christmas season than during other 


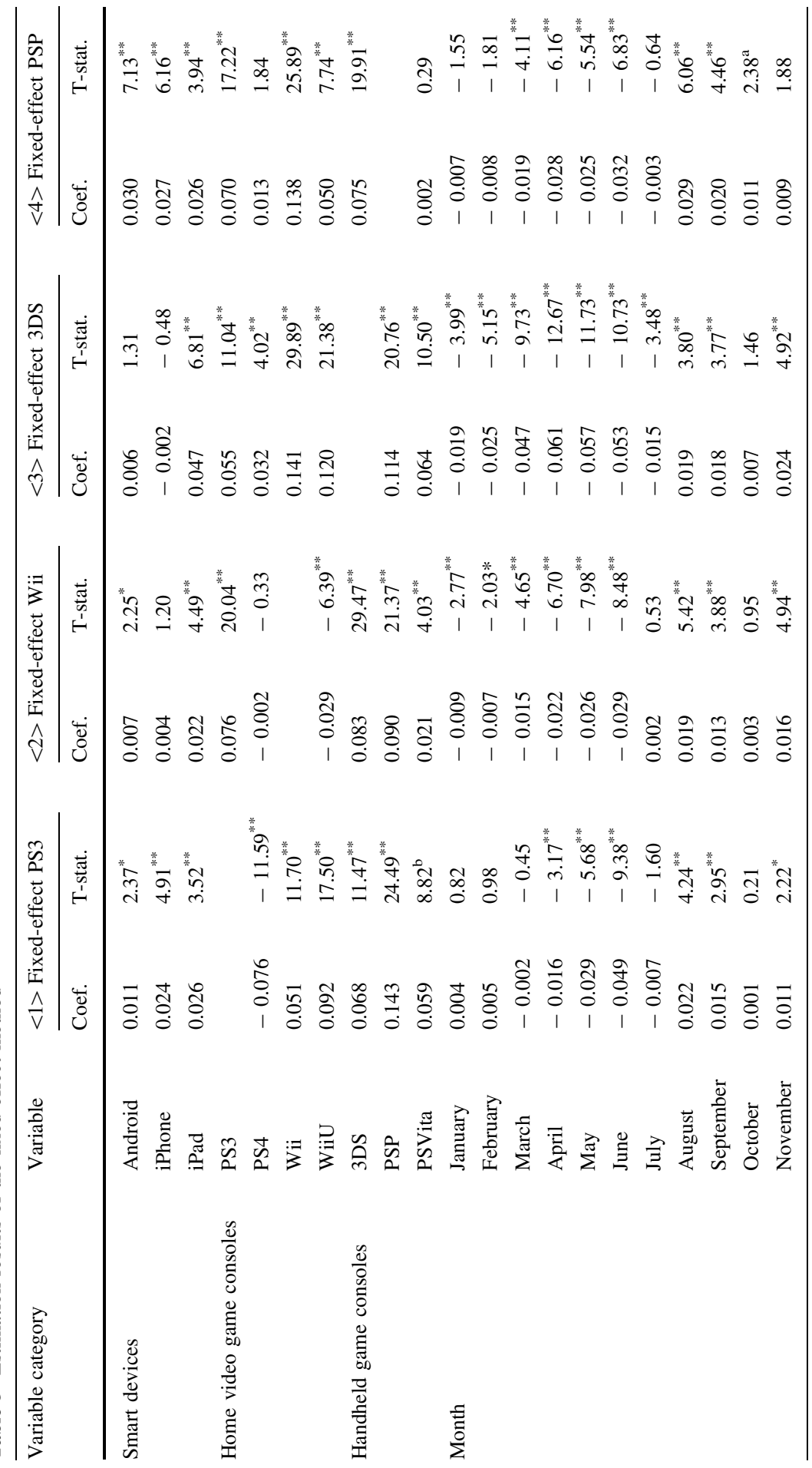




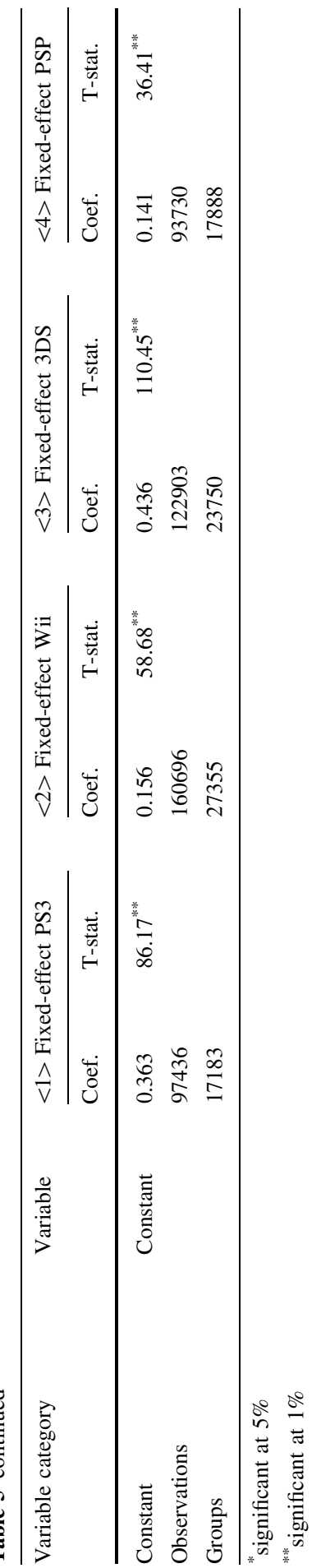




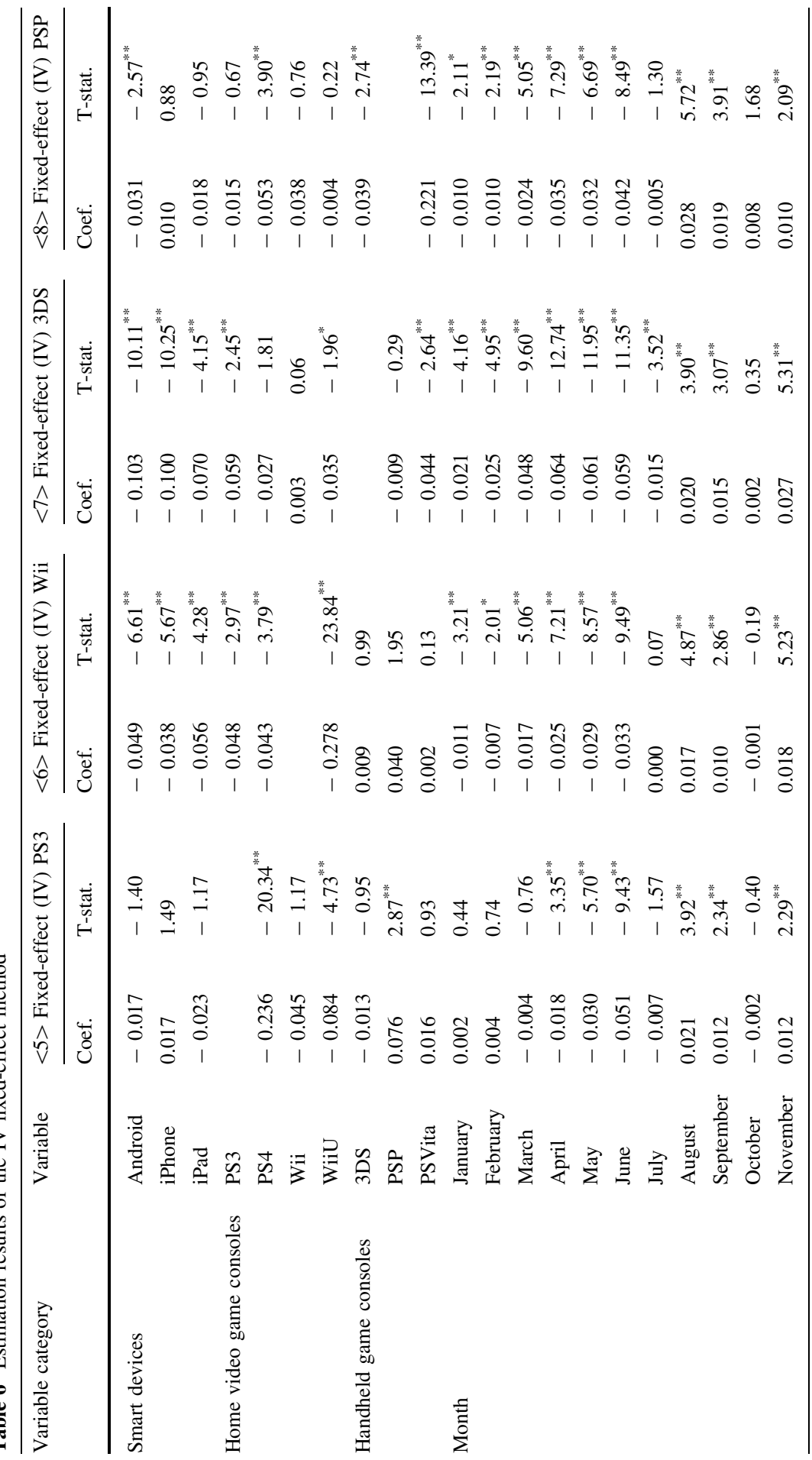




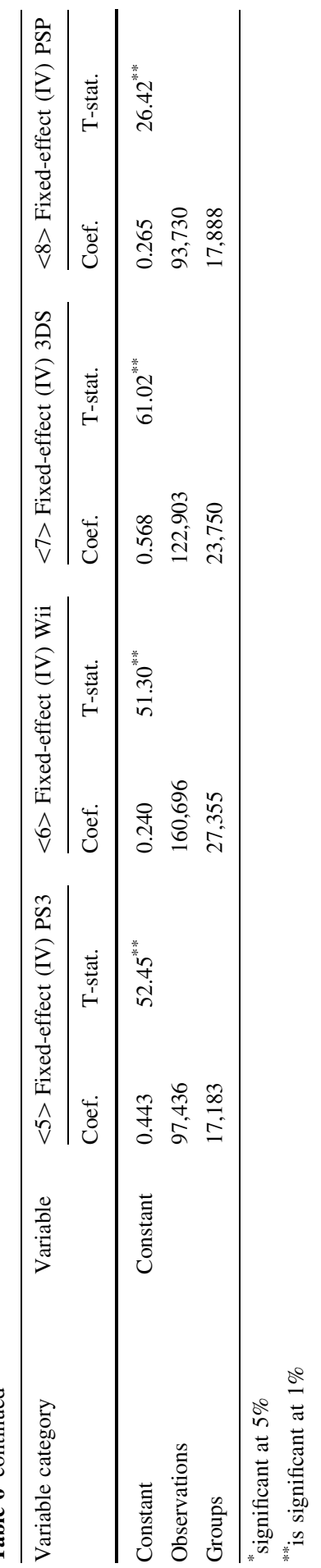


months. ${ }^{9}$ On the other hand, August, September, and November have significantly positive coefficients. This reason for this is that there is a summer vacation in August, and university students have summer vacation and "Silver week" in September, so these results are consistent. In November, the Christmas sales battles start, and consumers respond more sensitively than in December when the new popular software titles are released in the last week.

Regarding the parameters of video game consoles, all variables in all columns are significantly negative or insignificant except for PSP in column $\langle 5\rangle$, so they have the substitute effect on video game consoles or do not have any effects. In other words, playing the video game consoles causes a decrease in the play rate of the other consoles. PS4, especially, has a strong substitute effect (0.236) compared to PS3. However, PSP is in a complementary relationship with PS3. This result is caused because of PS3 remote play of PSP or the Internet via PS3. All these results can be interpreted naturally, so the models are reasonable.

All of the smart devices, which are the most important variables in this study, have significantly negative effects on Wii and 3DS. In addition, Android has a significantly negative effect on PSP. However, most smart devices have no significant impact on PSP and PS3. From these estimation results, we see that smart devices have substitution effects on Wii, 3DS, and PSP, but the effects on PSP are limited, and they do not have effects on PS3.

By comparing the type of game console, i.e., the home video game consoles and the handheld game consoles, we see that the substitution effects are up to approximately 0.103 on 3DS while up to approximately 0.056 on Wii. Although the effects on PSP are up to 0.031, there is no effect on PS3. These results imply that the substitution effects of mobile games on the home console games are smaller than on the handheld console games. For this reason, both the handheld game consoles and smart devices are superior in portability, so players can use them at any time and in any place. It is likely that the mobile games will replace the handheld console games because they can be played on a train or bus while commuting, or played with friends anywhere. However, the advantage of the home console games is that the games are richer in content and have more interesting characters, thus it is not likely that mobile games will replace console games.

Second, when comparing the developers, SIE and Nintendo, we see that the substitution effects on console games which are played on SIE's video game consoles are larger than on console games which are played on Nintendo's video game consoles. The reason is because both the main users of console games played on Nintendo's video game consoles and the main users of mobile games are casual gamers. On the other hand, most SIE game users are senior and core gamers, thus it is hard for them to change from console games to mobile games. Langlotz et al. [14] discusses how Microsoft and SIE produce high-technology products for the traditional hard-core gamer, while Nintendo's focus is on less technologically advanced targets, that is, casual gamers. Encarnaçao [15] also implies the same

\footnotetext{
9 Much game software is released at Christmas, so many consumers want to play the new games in December.
} 
proposition. Moreover, Rayna et al. [7] points out that the common characteristics between $\mathrm{Wii}$ and the mobile games are that their users are casual gamers.

All in all, the substitution effects are as small as 0.1 at the maximum, and the effects on PS3 and PSP are almost negligible. Therefore, the following hypothesis in Sect. 2 is accepted.

Hypothesis: Mobile games have few substitution effects on console games.

\section{Conclusion}

In this research, we analyzed the substitution effects ${ }^{10}$ of mobile games on console games. As a result of the analysis, we found that the substitution effects of smart devices on 3DS, Wii, and PSP were recognizable, but the substitution effects did not have a significant influence on PS3, and the substitution effects on PSP were limited. In addition, the substitution effects on the home console games were smaller when compared with handheld console games. Furthermore, the substitution effects on console games of SIE's video game consoles were smaller than that of Nintendo's video game consoles. From the above, although the substitution effects are present in console games played by many casual users and on console games where the play situations are similar to mobile games, they were at most 0.1. Therefore, the substitution effects were limited.

Our results suggest that mobile games are pioneers in the new market at least during our observation period. In the video game industry, technological innovation constantly occurs and new services spread, but if existing services and new services are sufficiently differentiated, they can coexist in the same market. In addition, mobile games using characters and the storyline of console games have become popular in recent years, so a deepening cooperation between existing services and new services is considered important for industrial development.

However, this research has problems. First, the result of this research may be peculiar to Japan. Since there are many commuters by train in Japan, they play mobile games when they go out, and play situations are different from console games. On the other hand, in North America, for example, mobile games are often played at home with tablet devices, so play situations are similar to console games.

Second, we use only data from August 2014 to August 2015. Figure 1 from the paper, however, shows a dramatic difference in console games peaking in 2007 , so we should also use data from before 2007 if possible. Unfortunately, we cannot obtain data before August 2014, but this period (from August 2014 to August 2015) does not have problems for the following reason. The substitution effect referred to in this research is "whether to stop playing a console game by playing a mobile game" is not a macroeconomic substitution effect. We think that this consumer behavior has hardly changed.

${ }^{10}$ The substitution effect referred to in this research of "whether to stop playing a console game and start playing a mobile game" is not a macroeconomic substitution effect. We assume that this consumer behavior has hardly changed. 
Regardless, this paper has the significance of showing quantitatively the magnitude of the substitution effect in the video game market where new services created by technological innovation have grown rapidly. As mentioned in Sect. 1, such phenomena are occurring not only in the video game industry. It is necessary to verify the substitution effects and the complementary effects through empirical research and consider the direction of industrial policy through business.

Acknowledgements The authors are grateful to gameage R\&I Co., Ltd., for sharing their dataset with us.

Open Access This article is distributed under the terms of the Creative Commons Attribution 4.0 International License (http://creativecommons.org/licenses/by/4.0/), which permits unrestricted use, distribution, and reproduction in any medium, provided you give appropriate credit to the original author(s) and the source, provide a link to the Creative Commons license, and indicate if changes were made.

\section{References}

1. Nguyen, G., Dejean, S., \& Moreau, F. (2014). On the Complementarity between Online and Offline Music Consumption: the Case of Free Streaming. Journal of Cultural Economics, 38(4), 315-330.

2. Koh, B., Murthi, B. P. S., \& Raghunathan, S. (2014). Shifting demand: online music piracy, physical music sales, and digital music sales. Journal of Organizational Computing and Electronic Commerce., 24(4), 366-387.

3. Forman, C., Ghose, A., \& Goldfarb, A. (2009). Competition between local and electronic markets: how the benefit of buying online depends on where you live. Management Science, 55(1), 47-57.

4. Goldfarb, A., \& Tucker, C. (2011). Advertising Bans and the Substitutability of Online and Offline Advertising. Journal of Marketing Research, 48(2), 207-227.

5. Anderson, C. (2009). Free: the future of a radical price. Random House.

6. Davidovici-Nora, (2014). Myriam: paid and free digital business models innovations in the video game industry. Communications and Strategies, 94, 83-102.

7. Rayna, T., Striukova, L. (2014). Few to Many': change of business model paradigm in the video game industry. Digiworld Economic Journal, (94), 61-81.

8. Benghozi, P. J., Salvador, E., \& Simon, J. P. (2015). Models of ICT innovation. JRC Science and Policy Report. European Union.

9. van Dreunen, J. (2011). A business history of video games: revenue models from 1980 to today. The game behind the video game: business, regulation, and society in the gaming industry. New Brunswick, New Jersey: Rutgers University.

10. Ernkvist, M. (2015). Velocity shifts in the creative economy: incumbent-entrant dynamics in the emergence of Japanese social games. Ratio Working Papers, (267). The Ratio Institute.

11. Heier, C. (2015). Free to play: mobile gaming and the precipitous rise of freemium. The Review: A Journal of Undergraduate Student Research., 16, 5-11.

12. Vankka, E. (2014). Free-to-play games: professionals' perceptions. Master's Thesis (p. 74). University of Tampere.

13. Wooldridge, J. M. (2010). Econometric analysis of cross section and panel data (p. 1096). MIT press.

14. Langlotz, A. C. H., Rhode, M., \& Whaley, C. (2008). Video games industry overview: an analysis of the current market and future growth trends. International Business Project.

15. Encarnaçao, L. M. (2009). On the future of serious games in science and industry. Proceedings of CGames, 9-16. 